\title{
Contribuição da prática em sala de aula na formação de novos docentes: relato de experiência de um Bacharel
}

\author{
Contribution of classroom practice to the training of new teachers: a Bachelor's experience report \\ Contribuciones de las practicas en la clase para la formación de nuevos docentes: relato de
}

experiencias de un Licenciado

Recebido: 29/12/2020 | Revisado: 06/01/2021 | Aceito: 10/01/2021 | Publicado: 12/01/2021

\author{
Raí Emanuel da Silva \\ ORCID: https://orcid.org/0000-0002-4266-0475 \\ Universidade Federal do Piauí, Brasil \\ E-mail: raiemanuel@ hotmail.com \\ Rosemary Meneses dos Santos \\ ORCID: https://orcid.org/0000-0003-1620-9653 \\ Universidade Federal do Delta do Parnaíba, Brasil \\ E-mail: rosemary-phb@hotmail.com
}

\begin{abstract}
Resumo
O estudo tem como objetivo relatar a experiência e atividades desenvolvidas por um Bacharel na execução do seu Estágio de Docência, enquanto aluno de pós-graduação a nível de Mestrado Acadêmico. O estágio foi realizado no curso de Bacharelado em Biomedicina, da Universidade Federal do Delta do Parnaíba. Ficou a cargo do estagiário a seleção, elaboração e execução de aulas teóricas e práticas. As atividades foram realizadas nas disciplinas de Bacteriologia, Virologia e Práticas em Biomedicina II. Sob supervisão da professora responsável pelos componentes curriculares, o estagiário cumpriu a carga horária total de 30 horas, executando as atividades propostas. A experiência representou um momento de aproximação com a sala de aula, sendo possível compreender os desafios da docência no ensino superior. A execução tanto de aulas teóricas como também de aulas práticas em laboratórios, contribuiu para o entendimento do processo de formação de novos biomédicos. Uma vez que profissionais Bacharéis não contemplam em sua formação a preparação para carreira docente, tal atividade representou uma importante estratégia para formação de um novo Mestre na área da saúde.
\end{abstract}

Palavras-chave: Docência; Ensino superior; Bacharel; Mestre.

\begin{abstract}
The present study aims to report the experience and activities developed by a Bachelor in the execution of his Teaching Internship, as a postgraduate student at Master's level. The internship was carried out in the course of Bachelor in Biomedicine, of the Federal University of Delta of Parnaíba. The trainee was responsible for selecting, preparing and performing theoretical and practical classes. The activities were conducted in the disciplines of Bacteriology, Virology and Practices in Biomedicine II. Under the supervision of the responsible teacher for those curricular components, the trainee fulfilled a total workload of 30 hours, executing the proposed activities. That experience represented a moment of approximation to the classroom environment, making possible to understand the challenges of teaching in higher education. The execution of both theoretical and practical classes in laboratories contributed to understanding the process of development of new biomedical scientists. Since professional Bachelor's did not include preparation for a teaching career, this activity represented an important strategy for the academic formation of a new Master in the health field.
\end{abstract}

Keywords: Teaching; Higher education; Bachelor; Master.

\section{Resumen}

El estudio tiene como objetivo reportar la experiencia y actividades desarrolladas por un Licenciado en la ejecución de su Pasantía Docente, como estudiante de posgrado en el nivel de Maestría Académica. La pasantía se realizó en la Licenciatura en Biomedicina de la Universidad Federal del Delta do Parnaíba. El becario se encargó de la selección, preparación y ejecución de las clases teóricas y prácticas. Las actividades se realizaron en las disciplinas de Bacteriología, Virología y Prácticas en Biomedicina II. Bajo la supervisión del docente responsable de los componentes curriculares, el pasante cumplió con la carga de trabajo total de 30 horas, realizando las actividades propuestas. La experiencia representó un momento de aproximación con el aula, permitiendo comprender los desafíos de la docencia en la educación superior. La ejecución de clases teóricas y prácticas en laboratorios, contribuyó a la comprensión del proceso de formación de nuevos biomédicos. Dado que los profesionales de Licenciatura no consideran en su formación prepararse para la carrera docente, esta actividad representó una estrategia importante para la formación de un nuevo Máster en el área de la salud. 
Palabras clave: Docencia; Educación superior; Licenciatura; Maestría.

\section{Introdução}

A globalização tem promovido diversos avanços na sociedade. A exemplo disso o processo de formação de novos profissionais, nas mais diversas áreas, tem se tornado constante, permitindo que a aquisição de conhecimento seja um fenômeno transformador (Fernandes, 2017). As Instituições de Ensino Superior (IES) representam a base para a formação da nova classe trabalhadora, sendo um espaço grandioso para tal. Ao passo que forma novos profissionais, esta também se encontra apta à formação de novos Mestres por meio da pós-graduação.

Com o objetivo de formar novos professores, frente a expansão do ensino superior, os Programas de Pós-Graduação a nível de Mestrado Acadêmico, presentes em diversas IES, permitem que os alunos dos programas possam vivenciar a experiência docente por meio da realização de Estágio Docência (Joaquim, Vilas Boas \& Carrieri, 2013). A Coordenação de Aperfeiçoamento de Pessoal de Nível Superior (CAPES), órgão de fomento que regulamenta a concessão de bolsas de estudos à alunos de pós-graduação, por meio da Portaria $\mathrm{n}^{0} 76$ de 2010, estabelece como exigência à alunos contemplados com este recurso, o cumprimento de atividades docentes a nível de Graduação, como componente da sua formação acadêmica (Brasil, 2000).

Desta forma, a realização do estágio em sala de aula representa um momento para a execução de um planejamento criterioso, sendo possível ao estagiário estabelecer a troca de experiências na construção do conhecimento dos discentes. Nesse sentido, a relação existente entre aluno, professor e o conhecimento, é o alicerce desta construção (Quadros et al., 2012).

A prática docente encontra-se intimamente relacionada com ações didática-pedagógicas a fim de garantir a transmissão do conhecimento. Neste sentido, Freitas et al. (2016) ressalta a importância do conhecimento pedagógico no processo de ensino-aprendizagem, correspondendo a uma atividade abrangente, em que cabe ao docente considerar os princípios básicos da aprendizagem.

Muitos cursos de bacharelado não possuem em sua grade curricular componentes que aproximem o acadêmico da prática docente, não credenciando-o para esta área. Desta forma, os Bacharéis buscam por uma qualificação profissional que permita-o atuar como educador e transmissor do conhecimento, seguindo critérios pedagogicamente estabelecidos. No ambiente da pós-graduação, a nível de Mestrado Acadêmico, a inserção e a vivência no ambiente da sala de aula representam um dos maiores desafios na formação dos novos Mestres (Santos, 2013).

Com isso, tal problemática representou um questionamento a ser compreendido, no sentido de entender a maneira como o estágio docente pode contribuir para a formação de um novo Mestre. E com isso, entender, na linha de base, como ocorre a formação docente na educação superior no Brasil. Assim, este trabalho teve como objetivo relatar as atividades desenvolvidas e a experiência vivida no exercício da prática docente por um Mestre, no cumprimento do seu Estágio Docência em uma instituição pública de ensino, como requisito obrigatório do Programa de Pós-Graduação ao qual o mesmo foi vinculado.

\section{Metodologia}

Trata-se de um estudo descritivo, com análise qualitativa, onde apresenta-se a experiência vivida por um Mestre em Farmacologia, a partir da realização do Estágio Docência durante sua formação no curso de Mestrado do Programa de PósGraduação em Farmacologia da Universidade Federal do Piauí. Nos relatos de experiências, considera-se a descrição e a análise de um caso, de maneira mais detalhada e completa possível. Assim, é plausível oferecer aporte para reflexões relacionadas ao fenômeno em estudo (Pereira et al., 2018). 
O estágio teve como objetivo geral promover a participação nas atividades didático-pedagógicas no Ensino de Graduação. Dentre os objetivos específicos, incluíram-se: adquirir e aprimorar os conhecimentos na área de atuação, aperfeiçoando a formação do aluno de pós-graduação para o exercício da docência no ensino superior; aproximar o pósgraduando da realidade da sala de aula e consolidar os conceitos aprendidos, sintetizando-os e aprimorando-os na prática.

As atividades de estágio foram desenvolvidas no curso de Bacharelado em Biomedicina, oferecido pela Universidade Federal do Delta do Parnaíba-UFDPar, Campus Ministro Reis Velloso, em Parnaíba-PI. O mesmo foi executado através de atividades nas disciplinas de Bacteriologia, Práticas em Biomedicina II e Virologia, todas componentes curriculares obrigatórios do curso. Estas são disciplinas ministras por docente do quadro permanente do referido curso de Graduação.

Os temas que ficaram sob responsabilidade do estagiário foram previamente selecionados pela docente supervisora, de maneira em que se pudessem contemplar as três disciplinas ministradas pela mesma no curso de Biomedicina. Caracteristicamente, estas se encontram inseridas/relacionadas dentro da área da Microbiologia, ciência responsável pela compreensão dos processos básicos da vida, bem como pela aplicação dos conhecimentos da área em prol da humanidade (Madigan et al., 2010). Dentre os temas de aulas teóricas e práticas que ficaram sob responsabilidade do estagiário, incluíramse: Controle das Doenças Virais e Agentes Antivirais, Coloração de Gram, Controle de Microrganismos, Staphylococcus sp e Streptococccus sp., as quais foram ministradas seguindo o cronograma estabelecido para cada disciplina.

A carga horária total cumprida pelo estagiário foi de 30 horas, distribuídas entre diferentes atividades, contemplando: análise e seleção de referências bibliográficas pertinentes para a elaboração de aulas teóricas referentes aos assuntos préselecionados pela professora supervisora do estágio; elaboração dos slides de apresentação para aulas teóricas, seguindo a proposta encaminhada; seleção, preparação e execução de atividades complementares em sala de aula, como estratégia de fixação do conteúdo ministrado na mesma.

Como atividade base e de extrema importância para experiência, realizou-se também aulas teóricas expositivas, a partir de conteúdos previamente determinados, bem como auxílio aos discentes, em horário extra classe, quanto às dúvidas sobre o conteúdo ministrado. O estagiário ainda participou da concepção de questões para avaliações escritas ao fim de cada unidade ministrada.

O estágio foi desenvolvido implementando a apresentação de aulas expositivas, por meio de recursos tecnológicos (notbook, data-show, apresentador multimídia), pincéis e quadro branco. Além destas, a inserção de conteúdos e atividades extras ao final das aulas expositivas, permitiu ao estagiário fornecer aos discentes um momento de reflexão diante do conteúdo ministrado. Ao final do período de estágio, um relatório final foi elaborado, sendo possível descrever as atividades executadas bem como realizar uma autoavaliação da experiência vivida.

Após a conclusão do referido estágio, foi realizada uma reflexão acerca da supracitada experiência, no intuito de contribuir com os saberes teórico-práticos envolvidos no ensino superior. Desta maneira, apresenta-se o presente relato de experiência onde as informações são expostas de maneira descritiva, com o objetivo de reunir as ideias acerca do tema proposto pelo estudo.

\section{Resultados e Discussão}

A apresentação de experiências realizadas por estudantes já é algo consolidado na literatura, sendo esta uma forma de expor as vivências conduzidas ao longo de sua formação acadêmica (Portilho et al., 2021). Neste sentido, por representar o componente curricular de uma formação, o estágio pode ser compreendido como um processo assíduo, por parte do estudante, e uma atividade educativa e complementar no processo de ensino-aprendizagem no âmbito da sala de aula, aproximando-o assim da realidade profissional (Lima \& Braga, 2016). No presente relato apresenta-se a experiência vivida por um Biomédico 
e Mestre em Farmacologia, em detrimento da realização do seu Estágio Docência, componente obrigatório da formação acadêmica, enquanto aluno de um programa de Pós-Graduação.

Uma vez que nos cursos de Bacharelado (grau de formação profissional do pós-graduando) a prática docente não representa umas das demandas abordadas em tal nível de ensino, o cumprimento de componentes curriculares, ofertados pelos programas de pós-graduação, insere os Bacharéis em um contexto pedagógico, aproximando-os de estratégicas a serem empregadas no processo de ensino-aprendizagem. Neste sentindo, o Mestrando previamente cumpriu o componente curricular "Estratégias Pedagógicas no Ensino em Ciências Biomédicas", preparando-se desta maneira para a realização futura do Estágio Docência.

O desenvolvimento das ações pelo estagiário iniciou pelo estabelecimento de um cronograma junto à professora supervisora e responsável pelas disciplinas ministradas. A partir disso, coube ao mesmo selecionar e estabelecer critérios para a preparação das aulas teóricas, a fim de garantir a qualidade do conteúdo ministrado, bem como seguir a ementa das disciplinas exigida pelo curso de graduação.

O estágio docência representa um momento onde o pós-graduando vivencia a prática em sala de aula, de maneira que o contato com a classe discente permite-o experimentar os desafios da educação superior, estabelecendo critérios que o auxiliem no processo de ensino-aprendizagem, preparando-o para o ambiente didático e pedagógico. Além disso, a prática também permite o seu crescimento profissional e intelectual (Araújo, 2013).

Uma vez preparadas, as apresentações em slides, referente a cada conteúdo, foram então analisadas quanto ao conteúdo e preparação pela professora supervisora, certificando-se desta forma da abordagem estabelecida pelo estagiário. Diante da análise e da concordância do conteúdo selecionado, as aulas foram então ministradas, cumprindo a carga horária destinada para cada encontro, perfazendo um total de duas horas/aula.

A execução das aulas teóricas permitiu enfrentar o desafio da sala de aula, momento em que de fato, a prática docente se fez presente. Neste ambiente, a transmissão do conhecimento teve como alicerce todo o aprendizado adquirido ao longo da formação do estagiário. Os conhecimentos específicos da área bem como os saberes pedagógicos promoveram a realização satisfatória das aulas expositivas, as quais, segundo Souza Gil et al. (2012), apresentam benefícios no desenvolvimento de um curso, permitindo o primeiro contato com um tema novo, através de um discurso oral e/ou escrito.

A atividade caracteristicamente prática, proporcionou ao pós-graduando além da experiência, conhecimentos para o ato de lecionar, o qual representa um objetivo claro e intrinsecamente voltado aos cursos de licenciatura. $\mathrm{O}$ estágio contribuiu significativamente para sua formação como Mestre, situando-o no ambiente pedagógico e fornecendo assim subsídios para a compreensão da formação do professor do Ensino Superior.

As ações realizadas tanto no ambiente da sala de aula, como também as atividades extraclasse, no preparo dos temas de cada aula, foram atividades desenvolvidas de maneira semelhante ao apresentado por Oliveira \& Silva (2012), demonstrando que estágios docentes estabelecem critérios similares em muitas IES, cumprindo assim os objetivos determinados.

A utilização de metodologias tradicionais e/ou complementares somadas ao uso de recursos pedagógicos, contribuíram significativamente para o processo ensino-aprendizagem dos alunos do curso de Biomedicina. A partir do uso de recursos tecnológicos como notbook e data-show, as aulas expositivas tornaram-se o momento onde o estagiário, de fato, praticou a atividade docente, pondo em execução a sua prévia preparação. Além disso, foi possível estabelecer um espaço em que os alunos pudessem esclarecer dúvidas referentes ao conteúdo abordado, a fim de garantir a aquisição do conhecimento necessário.

Além de aulas teóricas expositivas, o estagiário também foi responsável pela execução de aulas práticas em laboratórios da instituição. As atividades desenvolvidas aperfeiçoaram o conhecimento teórico, aproximando o profissional da 
vivência laboratorial como ferramenta no processo de formação de novos profissionais Biomédicos, preconizando as boas práticas laboratoriais. Neste momento, a troca da sala de aula pelo laboratório, representou um espaço diferenciado, onde foi possível executar de maneira prática os conhecimentos teóricos adquiridos.

O desenvolvimento das atividades de estágio, e neste caso, em cursos de Graduação, promove a conciliação dos conhecimentos teóricos, aplicando-os diretamente na transmissão do saber de maneira prática na formação de novos profissionais (Santos et al., 2015). Além disso, esta etapa permite o professor em formação compreender que o seu papel enquanto formador vai além de apenas reproduzir o conhecimento científico, mas também o de estimular o senso crítico no seu alunado, objetivando a reflexão diante do ensino promovido, de maneira que o mesmo seja o principal construtor do seu próprio conhecimento (Freitas, 2016).

O cumprimento do componente curricular aproximou o pós-graduando da vivência e realidade da prática docente. Na oportunidade, foi possível assimilar o conhecimento teórico com a execução de atividades importantes a fim de assegurar a transmissão do conhecimento a nível de Graduação. Neste sentido a seleção de conteúdo, a elaboração e a preparação de aulas teóricas, representaram ações básicas destinadas a estruturação do conhecimento a ser abordado em sala de aula. Estas foram assim responsáveis por estimular no estagiário o senso crítico científico, tornando-o capaz de discernir a relevância do conteúdo selecionado, tendo como foco principal a formação de profissionais capacitados a exercerem a sua profissão.

Conforme apresentado por Moreira (2015), existe uma necessidade de aperfeiçoamento na formação do professor, onde este deve estar constantemente atualizado através de diferentes leituras, compreendo de maneira detalhada situações inerentes ao ambiente da sala de aula, como por exemplo o processo de ensino-aprendizagem, a relação professor-aluno e as estratégias de ensino a serem implementadas.

Segundo Lopes (1996) o processo ensino-aprendizagem tem suma importância no ensino superior, onde esse representa uma interação dinâmica capaz de fornecer espaços para a contextualização, a socialização, bem como a transferência e a transformação do conhecimento, por intermédio da relação existente entre docente e discente. Ainda segundo o autor, torna-se evidente que tal processo ainda contribui para a preparação do corpo discente no âmbito profissional.

Notadamente o referido estágio representou um grandioso desafio para o estagiário, tendo em vista que essa foi sua primeira experiência neste nível de ensino, além da ausência de fundamentação teórica durante sua graduação em Biomedicina. Contudo, de maneira satisfatória a experiência o permitiu estabelecer uma correlação com o conhecimento profissional adquirido ao longo do seu processo de formação e a carreira como docente na área da saúde.

\section{Considerações Finais}

Considerando a proposta da agência de fomento que institui o Estágio Docência como um componente obrigatório para os alunos de pós-graduação bolsistas, esta representa uma estratégia que reflete positivamente na formação de novos Mestres. Esta consideração torna-se ainda mais pertinente quando se trata de profissionais Bacharéis, os quais muitas das vezes não adquirem contato com ambiente docente ao longo de sua formação profissional. Desta forma, percebe-se a contribuição dos programas de Pós-graduação como ferramenta para a qualidade do ensino superior no Brasil.

Diante da realização das atividades relatadas no presente estudo, destaca-se a imensurável contribuição do Estágio Docência para a formação de um Bacharel como novo Mestre na área da saúde. A presença na sala de aula estabeleceu um momento para uma experiência valiosa, que melhorou e aperfeiçoou o seu desenvolvimento diante da futura carreira docente.

O desenvolvimento de diferentes atividades, como a seleção de conteúdos que contemplassem a ementa da disciplina, bem como a elaboração, preparação e execução de aulas teóricas, além de avaliações escritas, permitiu o reconhecimento dos desafios da docência. Com isso, foi possível compreender de que maneira o professor do ensino superior deve encontrar-se apto às mais diferentes situações, estabelecendo critérios e alternativas que o auxiliem no processo de ensino-aprendizagem. 
Assim, reitera-se a importância de novos estudos que visem expandir os conhecimentos acerca da contribuição do estágio docência, durante os cursos de pós-graduações no Brasil, na formação de novos professores do ensino superior. Uma análise continuada desse processo construtivo permitirá compreender a eficácia das medidas implementadas pelos órgãos de fomento, e por conseguinte, a qualidade dos programas de pós graduação, no que diz respeito à formação de futuros docentes.

\section{Referências}

Araújo, G. C. C. (2013). Estágio Docente Na Disciplina Metodologia Da Geografia No Curso De Graduação Em Geografia Da Universidade De Brasília. Revista de Ensino de Geografia, 4(6), 169-174. http://www.revistaensinogeografia.ig.ufu.br/N.6/Rel4v4n6.pdf.

Brasil. Coordenação de Aperfeiçoamento de Pessoal de Nível Superior (BR). Resolução n. ${ }^{\circ}$ 013/00, de 27 de abril de 2000 . Regulamento do Programa de Demanda Social - DS. CAPES; 27 abr 2000. Seção 1.

Fernandes, J. S. (2017) Formação, identidade docente e os dilemas no exercício da profissão. (Trabalho de Conclusão de Curso). Licenciatura Plena em Pedagogia, Centro de Formação de Professores, Universidade Federal de Campina Grande, Cajazeira, Paraíba, Brasil. http://dspace.sti.ufcg.edu.br:8080/jspui/bitstream/riufcg/5149/1/JOANE\%20DE\%20S\%c3\%81\%20FERNANDES.\%20TCC.\%20LICENCIATURA\%20EM\% 20PEDAGOGIA.2017.pdf.

Freitas, D. A., Santos, E. M. S., Lima, L. V. S., Miranda, L. N., Vasconcelos, E. L., \& Nagliate, P. C. (2016). Saberes docentes sobre processo ensinoaprendizagem e sua importância para a formação profissional em saúde. Interface-Comunicação, Saúde, Educação $20(57)$, 437-448. https://www.scielosp.org/pdf/icse/2016.v20n57/437-448/pt.

Gil, E. S. Garcia, E. Y. A., Lino, F. M. A., \& Gil, J. L. V. (2012). Estratégias de ensino e motivação de estudantes no ensino superior. Vita et Sanitas 6(1), 5781. https://repositorio.bc.ufg.br/bitstream/ri/18590/5/Artigo\%20-\%20Eric\%20de\%20Souza\%20Gil\%20-\%202012.pdf.

Joaquim, N. F., Vilas Boas, A. A., \& Carrieri, A. P. (2013). Estágio docente: formação profissional, preparação para o ensino ou docência em caráter precário?. Educação e Pesquisa 39(2), 351-365. https://www.scielo.br/pdf/ep/v39n2/a05v39n2.pdf.

Lima, M. S. L., \& Braga, M. M. S. C. (2016). Relação ensino-aprendizagem da docência: traços da Pedagogia de Paulo Freire no Ensino Superior. Educar em Revista (61), 71-88. https://www.scielo.br/pdf/er/n61/1984-0411-er-61-00071.pdf.

Lopes, A. O. (1996.) Relação de interdependência entre ensino e aprendizagem. In: Veiga IPA. Didática: o ensino e suas relações (6a ed.), 105-114. Papirus.

Madigan, M. T., Martinko, J. H., Dunlap, Paul V., Clark, D. P. (2010). Micro-organismos e Microbiologia. In: Microbiologia de Brock. (12a ed.), 1160. Editora Artmed.

Moreira, A. E. C. (2015). O papel docente na seleção das estratégias de ensino. In: XVI Semana da Educação e VI Simpósio de Pesquisa e Pós-graduacão em Educação do Departamento de Educação, 497-508.

Oliveira, M. L. C., \& Silva, N. C. (2012). Estágio de docência na formação do mestre em enfermagem: relato de experiência. Enfermagem em Foco 3(3), 131134. http://revista.cofen.gov.br/index.php/enfermagem/article/view/297.

Pereira, A. S., Shitsuka, D. M., Parreira, F. J., \& Shitsuka, R. (2018). Metodologia da pesquisa científica. UAB/NTE/UFSM. https://repositorio.ufsm.br/bitstream/handle/1/15824/Lic_Computacao_Metodologia-Pesquisa-Cientifica.pdf?sequence=1 .

Quadros, A. L., Silva, D. C., Silva, F. C., Andrade, F. P., Aleme, H. G., Oliveira, S. R., et al. (2012). A formação do professor universitário no percurso de pós-graduação em Química. Ciência \& Educação, 18(2), 309-321. https://www.locus.ufv.br/bitstream/123456789/17082/1/artigo.pdf.

Santos, K. C. G. (2013). O Estágio Docente e o Desenvolvimento de Competências: um estudo no Programa de Pós-Graduação em Administração da Universidade Federal da Paraíba. (Dissertação de Mestrado), Programa de Pós-graduação em Administração, Centro de Ciências Sociais Aplicadas, Universidade Federal da Paraíba, João Pessoa, Paraíba, Brasil. https://repositorio.ufpb.br/jspui/bitstream/tede/3835/1/arquivototal.pdf.

Santos, L. P. S., Miranda, S. S., Graça, C. C., \& Sobrinho, C. L. N. (2015). Estágio Docência Na Formação Do Mestre Em Saúde Coletiva: Relato De Experiência. Rev. Saúde. Com, 11 (4), 418-424. https://periodicos2.uesb.br/index.php/rsc/article/view/386/313. 